\title{
NAVEGA DARWIN... DESDE EL BEAGLE A INTERNET - REFLEXIONES SOBRE UNA VIDEOCONFERENCIA INTERACTIVA
}

\author{
MARIELA FONTAIÑA GAMINARA \\ Instituto de Formación Docente de Florida \\ Departamento de Florida \\ República Oriental del Uruguay \\ e-mail: almaleal@gmail.com \\ LUCÍA RUTH ROJAS MÉNDEZ \\ Instituto de Formación Docente de Florida \\ Centro Regional de Profesores-Centro \\ Departamento de Florida \\ República Oriental del Uruguay \\ e-mail:Irrojasm@gmail.com
}


Resúmen: Este trabajo relata la experiencia de comunicación entre comunidades de dos países: el Museo de Ciencias "Universum" de la Universidad Autónoma de México (UNAM) y el Instituto de Formación Docente del Departamento de Florida (República Oriental del Uruguay) a través de la modalidad de videoconferencia. El tema refiere a la visita de Charles Darwin al territorio de Uruguay y fue elaborado por las divulgadoras con aportes que contribuyeran al Mes de la Evolución que organiza anualmente el Museo Universum. Se detallan y fundamentan aspectos de la construcción e implementación de la propuesta y se reflexiona sobre los mismos.

Palabras Clave: Comunicación de la ciencia, Educación científica, Evolución biológica, TICs

\section{CHARLES DARWIN NAVEGA A PARTIR DO BEAGLE PARA INTERNET REFLEXÕES SOBRE UMA VIDEOCONFERÊNCIA INTERATIVA}

Resumo: Este trabalho relata a experiência de comunicação entre comunidades de dois países: a do Museu de Ciências Universum da Universidade Autónoma de México (UNAM) e a do Instituto de Formação Docente do Departamento de Florida (República Oriental do Uruguai) através da modalidade de videocoferencia. O tema refere à visita do naturalista Charles Darwin ao território do Uruguai e foi elaborado pelas divulgadoras com aportes que contibuíssem ao Mês da Evolução que organiza anualmente o Museu Universum. Detalham-se e fundamentam aspectos da construção e implementação da proposta e reflexiona-se sobre os mesmos.

Palavras chave: Comunicação da ciencia, Educação Científica, Evolução biológica, TICs

\section{CHARLES DARWIN SURFS FROM THE BEAGLE TO THE WEB REFLECTIONS ON AN INTERACTIVE VIDEOCONFERENCE}

Abstract:This work refers theexperience of communication, byvideo conference,
among communities of two countries: The "Universum Museum of Sciences"
from "Mexico Autonomous University" (UNAM), and the "Tertiary Teaching
Institute"(IDF) ofFlorida Department(Uruguay Republic). Theapplicationalludes
to the visit of Charles Darwin throughout Uruguay, and it has been made by the
divulgers with information that contributes to the "Evolution Month", annually
organized by "Universum Museum". Different subjects of this performance are
described, supported, analyzed and reflected on. Keywords: Communication of science, Science education, Biological evolution, TICS 
Las videoconferencias son una modalidad de divulgación de la ciencia que se implementan desde hace tiempo en el Uruguay. Este artículo trata de un evento de divulgación por videoconferencia efectuado desde una pequeña ciudad de la República Oriental del Uruguay (Florida) y el Museo Universum, perteneciente a la Universidad Nacional Autónoma de México (UNAM). El equipo de divulgación científica del Instituto de Formación Docente de Florida, Uruguay, respondió así a una invitación cursada por dicho Museo. El evento se llevó a cabo el 28 de noviembre de 2013, en el marco del las actividades del "Mes de la Evolución" que anualmente éste organiza. El tema fue "La Ruta de Darwin en el Uruguay". Como parte del mismo, se incluyó, un hallazgo paleontológico de repercusión mundial, referido al Mesosaurus hembra hallado en el Uruguay con un embrión en gestación en su interior. Ésta, es pariente cercana del Mesosaurus brasiliensis de la Formación Aratí, próxima a la Universidad de Santa María, lo que nos anima a divulgarlo en esta Revista.

La empresa uruguaya de telefonía pública (ANTEL) ha instalado salas de videoconferencia en la mayoría de las capitales de los Departamentos del país, y en la casi totalidad de los centros de Formación Docente, por lo que el evento se realizó en comunicación directa entre los centros mencionados de Uruguay y México. En Uruguay fue presenciada por miembros de la comunidad educativa y en México lo fue por dos grupos de estudiantes de dos escuelas secundarias preparatorias de la UNAM, por su personal y autoridades académicas.

La estructura de la videoconferencia fue diseñada en tres partes: la primera constó de la presentación de mapas para que los estudiantes mexicanos pudieran ubicar nuestro país en las Américas, y a nuestra ciudad, en Uruguay. Se incluyó el mapa político de nuestro territorio, en la época en que Charles Darwin nos visitó, para identificar la "Banda Oriental” a la que se refirió en el cuaderno del mismo nombre, que escribió durante su viaje. 


\section{El cuaderno de la Banda Oriental}

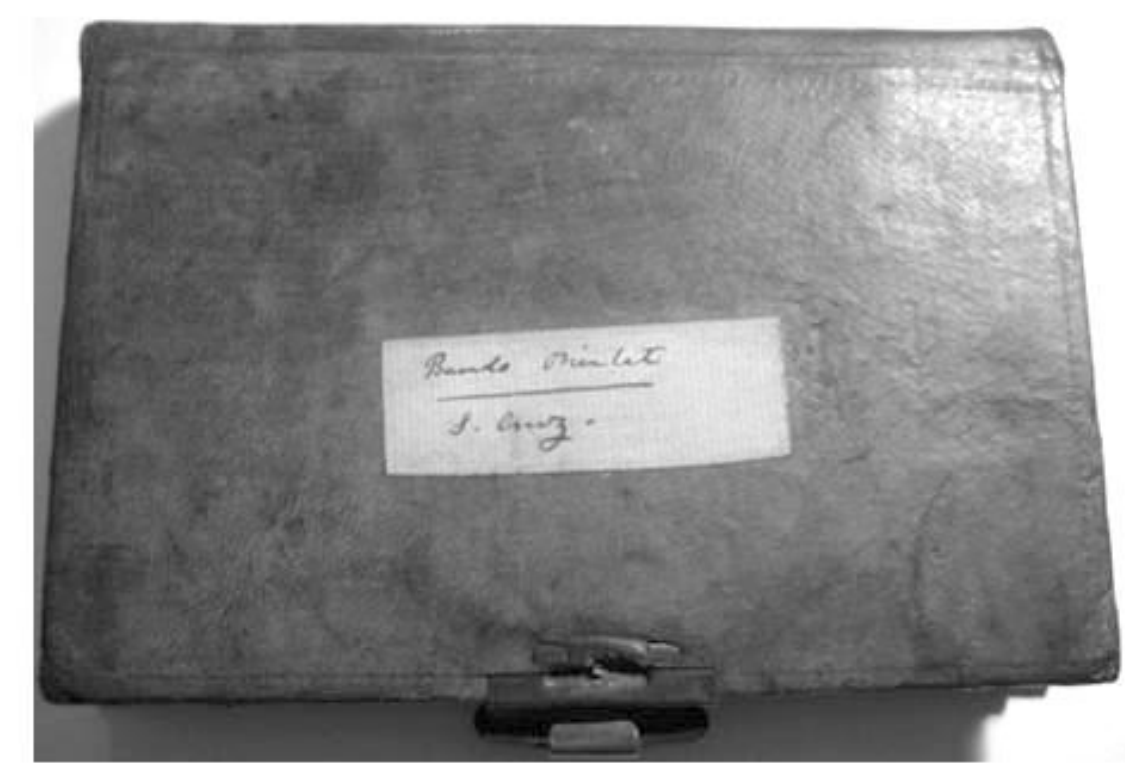

Se mostraron los ambientes e historia geológica de este territorio, relacionados a los relatos que realiza en él y en su "Diario del Beagle". También, se presentaron mapas de los recorridos del naturalista, realizados en dos años diferentes, en lo que actualmente es Uruguay así como mapas con las eras geológicas del mismo. Un apartado especial se dedicó al pensamiento y las emociones del joven Darwin, referidas al gaucho, las clases altas, los indios y la guerra para su exterminio.

Se presentaron tres videos breves, uno de ellos, sobre la fauna costera actual. La intención fue acercar imágenes de un territorio como el que halló Darwin durante su viaje, en las costas uruguayas, tanto atlántica como las del Río de la Plata. Se mostraron algunas especies zoológicas que figuran en sus registros, que aún se encuentran en las costas de los Departamentos de Rocha y Maldonado.

Son ecos actuales de su visita, anécdotas curiosas que relatamos, acerca de un plebiscito realizado por el pueblo "Villa Darwin" (Departamento de Soriano) tradicionalmente llamado "Sacachispas", para decidir si conservar uno u otro nombre. El resultado de la votación fue un empate técnico, con mutuas acusaciones de haber hecho trampa. 


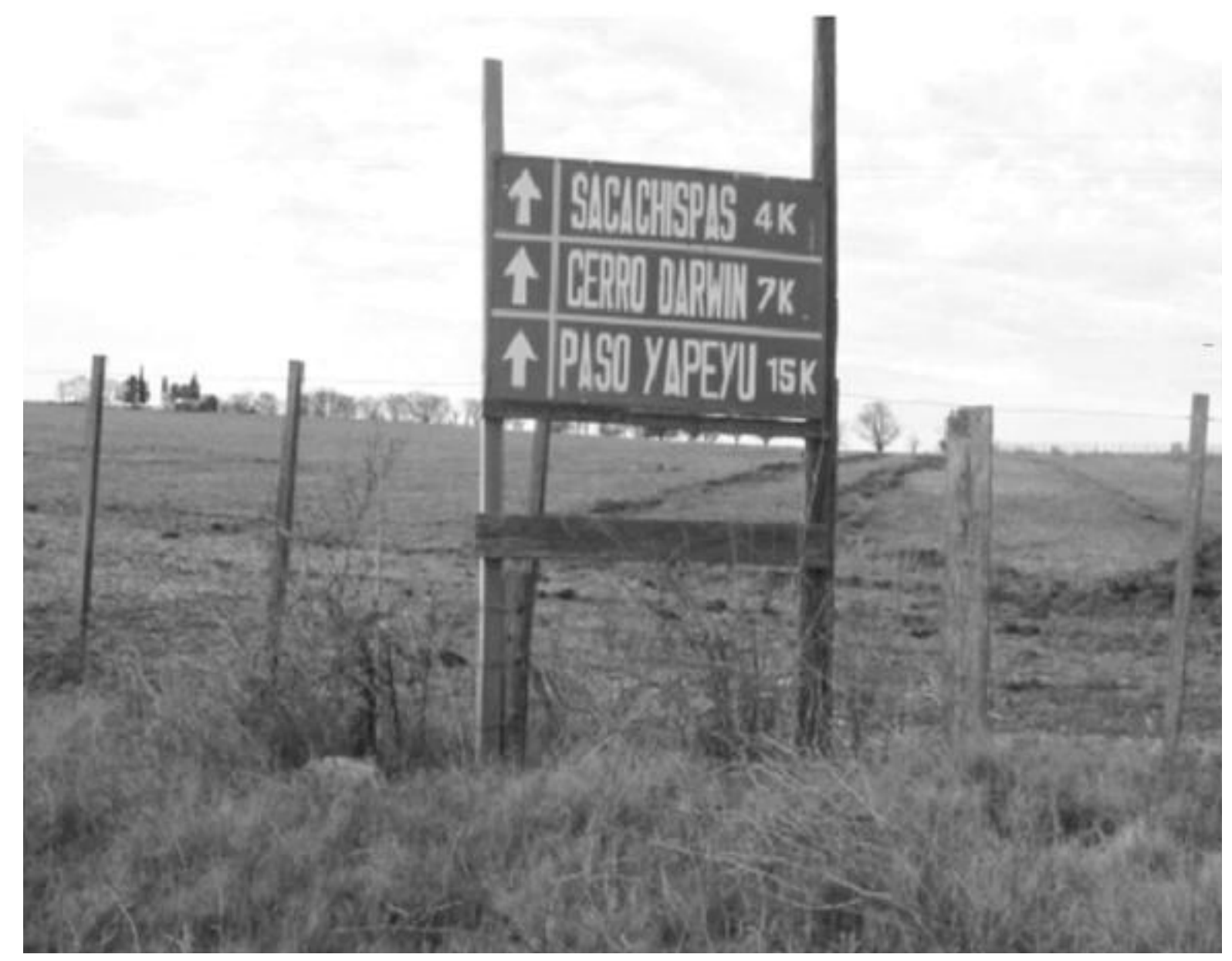

El lugar fue filmado y presentado para mostrar el escenario que visitó Darwin. Fueron exhibidas fotografías de las barrancas del arroyo Perico Flaco donde recolectó fósiles. Se tejieron lazos humanos, con fotos de un grupo de niños del cuadro de fútbol local, acompañada de preguntas, que buscaban orientar la observación hacia los rasgos de este grupo, que podrían ser los de cualquier país latinoamericano. El tercer video fue dedicado al Rincón de Darwin, (Departamento de Colonia), donde Darwin pasó unas cuantas semanas, realizó observaciones geológicas, faunísticas y acrecentó su colección de fósiles.

La segunda parte, se centró en la megafauna que recolectó y a sus testimonios sobre ello. Además hubo fotos de otras especies fósiles asociadas, con sus edades correlativas y escalas de tamaño, en relación a objetos conocidos. En este momento, introdujimos actividades interactivas con dos desafíos, que lograron divertir al público, en particular cuando se equivocaban.

La tercera parte trató de "Darwin hoy", en relación a la vigencia de la Teoría de la Evolución y vinculada a descubrimientos y evidencias de estudios recientes realizados en Uruguay, que respaldan la Teoría. Se presenta- 
ron observaciones y estudios zoológicos hechos por Darwin y el ornitólogo Gould referidos a las aves llamadas "calandrias" (Chalk-browed Mockingbird, Mimus saturninus) extraídas de sus textos. Sir Randall Keynes (tataranieto de Darwin), en su visita a Uruguay, en ocasión del aniversario 200 del nacimiento de Darwin y del 150 de la publicación de su "Origen de las especies", afirmó que la observación de estas aves con sus variaciones, fue el preámbulo de las conclusiones posteriores, que el naturalista realizó sobre los famosos pinzones de las Islas de las Galápagos.

MAYR (2001) en Qué es la evolución afirma que esta cadena de inferencias condujo a Darwin a la conclusión definitiva de que todos los organismos de la Tierra tenían ancestros comunes y que probablemente toda la vida en la Tierra había comenzado con un único origen de la vida.' Dibujo del libro " Voyage dans
l'Amérique Méridionale " (le Brésil, la république orientale de I'Uruguay, la République argentine, la Patagonie, la république du Chili, la république de Bolivia, la république du Pérou), exécuté pendant les années 1826,1827 , $1828,1829,1830,1831,1832$, et 1833 par Alcide d'Orbigny

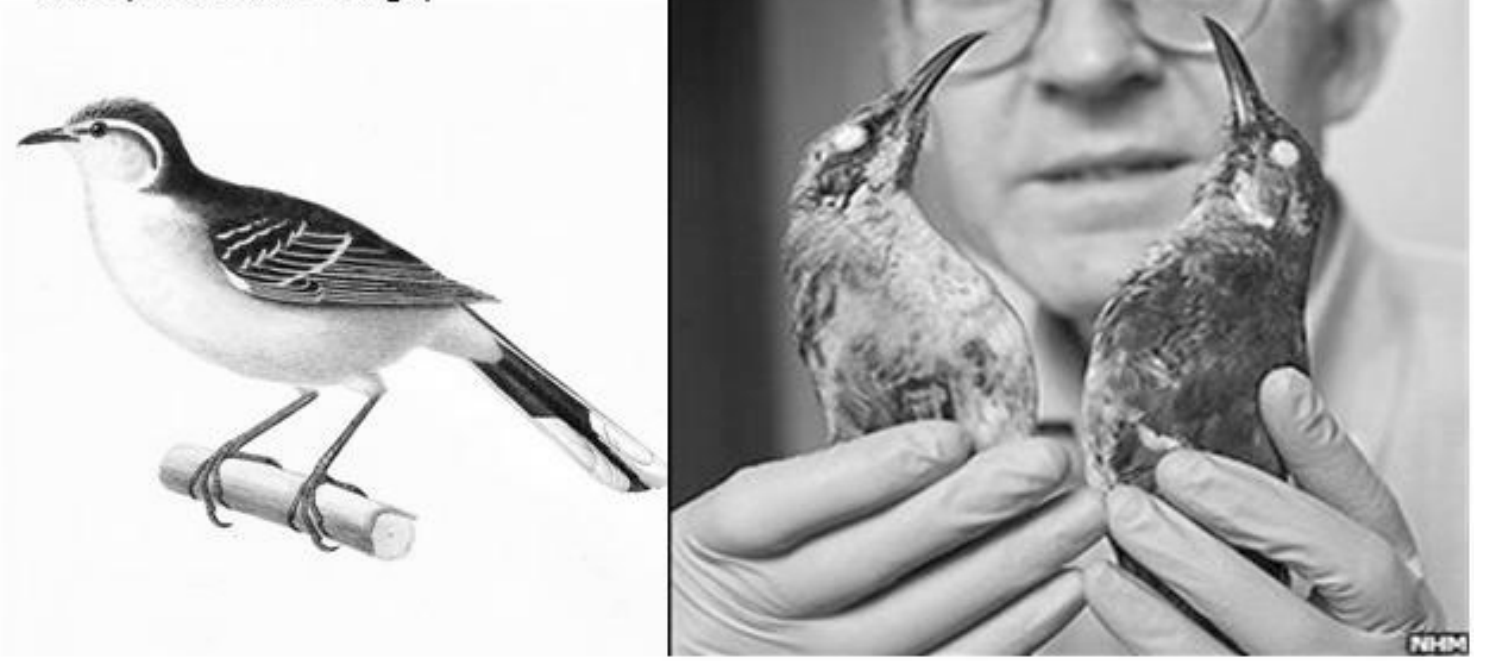

Se presentaron hallazgos del año 2012, en el Departamento de Cerro Largo, Uruguay, que respaldan la existencia de la Gondwana y la Teoría de la evolución.

1 En realidad, hay varias especies de sinsontes en América del Sur, por lo menos 3 de los cuales Darwin había observado en Argentina y Chile antes de llegar a Galápagos 


\section{COMUNICACIÓN DE LA CIENCIA: ¿QUÉ SE COMUNICA, CÓMO SE HACE, A QUIÉNES?}

\section{Elección y propuesta de la actividad:}

Objetivos: Son preguntas clave: ¿Qué deberían saber de nosotros? ¿Por qué querrían saberlo? ¿Cómo despertar su interés? ¿Cómo podrán usar la información y la experiencia recibidas?

Estas preguntas están pensadas para lograr el vínculo entre dos profesoras divulgadoras científicas de un instituto terciario de un pequeño país (generalmente desconocido) como es el Uruguay y jóvenes estudiantes secundarios y sus profesores de institutos de bachillerato de la UNAM. Es un encuentro asimétrico, y se ponen a prueba, la disposición al intercambio, la empatía y los canales horizontales de encuentro. También está en juego encontrar la motivación y el interés indispensable para intercambiar los contenidos científicos centrales de la comunicación así como los significados y proyecciones que la experiencia y el conocimiento puedan despertar.

En su estructura, atendimos a:

* provocar atención o curiosidad al apelar a grandes preguntas

* establecer vínculo con la cotidianeidad o a experiencias de vida

* presentar variedad de tópicos dentro de una línea conductora que mantuviera unidad temática (diferentes abordajes que nutren el tema, diversidad de presentaciones y contenidos audiovisuales como imágenes fijas, movimiento, colores, diseño, estilos, música, etc.)

*ofrecer tiempos acotados, de modo de mantener los niveles de atención

Los objetivos son componentes muy importantes del proceso de planificación y de acuerdo a ellos, se construyeron los criterios de evaluación. Se pensó en aspectos: Cognitivos: qué se pretende que aprendan los asistentes

Comportamentales: en qué se espera que los asistentes cambien sus percepciones y actitudes frente a la ciencia y al conocimiento científico y

Emocionales: cómo se espera que impacte a largo plazo la experiencia comunicativa, contribuya al desarrollo del interés por la ciencia, y al despertar de la empatía por la exploración e investigación científica.

\section{Diseño del audiovisual}

Aspectos tenidos en cuenta:

Colores llamativos, sin que saturaran la percepción. 
Títulos y gráficos provocativos que atrajeran la atención.

Enunciación de lo central del mensaje en los primeros 15-20 segundos de locución o en las primeras palabras del mensaje escrito.

Imágenes novedosas o que provocaran sorpresa.

Audio y video por lapsos de unos 3 minutos.

No se buscó ofrecer un espectáculo, ni sólo entretener, pero sí que la comunicación resultara interesante y fluida.

\section{Qué se tuvo en cuenta en esta presentación}

Existe consenso entre los neurobiólogos acerca de cómo funciona el cerebro frente a la comunicación, en este caso, de la ciencia. La comunicación para lograr objetivos genuinos deberá cumplir con ciertas condiciones:

- El inicio debiera ser dinámico y provocar atención activa.

- La disminución inevitable de la atención por sobrecarga psicológica, tendrá que coincidir con un quiebre del ritmo de exposición ( $v$. gr, que a los 10 minutos de comenzada la conferencia, comience la primera exhibición de video).

- La percepción no debiera resultar agobiante por exceso de estímulos e información.

- La atención debería ser redirigida cada tanto, hacia sonidos o música, y a continuación recomenzar la locución.

- La alocución no se usará en describir lo que el espectador ya ve o sabe, sino que debería enfocarse en aspectos que lo interpelen y lo inviten a la participación activa.

- El mensaje central y sus derivados principales tendrían que quedar claros

- La finalización sería un resumen corto, con solución de continuidad temática abierta, para futuros abordajes con maestros, expertos o los mismos productores del evento.

-Las actividades han que ser pensadas como propuestas que requieran alguna inversión mayor de energía, o el concentrar la atención para la reflexión.

Mirar, recorrer y escuchar, se consideran actividades pasivas (menor uso de energía por parte de los asistentes), por lo que se recomienda intercalar los momentos de atención pasiva con los de la atención activa.

Las propuestas interactivas deben utilizarse para ilustrar conceptos clave o para reforzar lo que aparece como novedoso. Abusar de ellas puede provocar cansancio o una sobrecarga sensorial. Una propuesta equilibrada, 
podría contener un $20 \%$ de interactividad, un $50 \%$ de imágenes fijas o de cortos párrafos de lectura y un 30\% de videos, animaciones o gráficos.

"Quienes producimos mensajes educativos sabemos que "lo formal" no es secundario ni accesorio; incide determinantemente en la capacidad comunicativa de los mensajes. Tan importantes como los contenidos que se pretenden comunicar es la forma en que éstos son comunicados."(KAPLÚN,1992:130). Éste, explicita aspectos importantes para favorecer la elaboración de la comunicación:

a) Brevedad y agilidad

b) Dosificación de los contenidos

c) Presencia de lo festivo y de elementos de humor

d) Prescripción del dramatismo

e) Proscripción de la "enseñanza" final

f) Personalización y humanización

g) Reducción del relato verbal

h) Realización técnicamente cuidada

\section{Elaborando la Videoconferencia...}

Una videoconferencia es un servicio multimedia que permite la interacción entre distintas personas o grupos de trabajo. Consiste en interconectar mediante sesiones interactivas a un número de interlocutores, que puedan verse y hablar entre sí. En función de la tecnología utilizada, permite además, el uso de otras herramientas como las presentaciones Power Point, pizarra electrónica, entre otros.

Otra conceptualización es "... el conjunto de hardware y software que permite la conexión simultánea en tiempo real por medio de imagen y sonido que hacen relacionarse e intercambiar información de forma interactiva a personas que se encuentran geográficamente distantes , como si estuvieran en un mismo lugar de reunión" (CABERO. J., 2000:98)

Las videoconferencias cuando incluyen interactividad, pueden ser especialmente útiles en despertar intereses, vocaciones y aumentar el conocimiento sobre temas científicos.

No se parte de la teoría del déficit, en donde hay un "experto que sabe" y el "vulgo que no sabe". No al menos desde la voluntad de intercambiar en el diálogo y no sólo imponer desde posiciones elitistas.

"La verdadera comunicación no está dada por un emisor que habla y un perceptor-recipiente que escucha, sino por dos seres o comunidades huma- 
nas que dialogan (aunque sea a distancia y a través de medios artificiales)" (KAPLÚN, 1990:17).

\section{¿CÓMO SE TOMAN LAS DECISIONES ACERCA DE QUÉ CONTENIDOS DIVULGAR Y CON QUÉ CRITERIOS?}

RENSBERGER (1997:11) enumera cinco criterios de valoración de la ciencia como noticia:

1) fascinación, 2) tamaño de la audiencia natural,3) importancia, 4) calidad de la investigación, 5) temporalidad.

Nos referiremos aquí, al valor de la fascinación, que es un criterio relacionado con la "singularidad e imprevisibilidad". Ésta puede ser de dos tipos: la que está relacionada con lo impresionante y asombroso (lo muy grande o lo muy pequeño) y la que está relacionada con lo extraño y extravagante. Esta última presenta la ciencia como pasatiempo, y destacamos que lo que más llamó la atención en los jóvenes mejicanos fue la presentación acerca de la megafauna. Se evidenció esto en el espacio destinado a preguntas.

Polino, C.(2003) dice que la circulación de la información científica en la sociedad implica una serie de procesos que a veces son conflictivos, a través de los cuales el conocimiento, códigos y valores de la ciencia y la tecnología se transmiten, se incorporan al acervo económico y cultural, devienen en cierto uso cotidiano de la ciencia y construyen, por fin, representaciones sociales diversas no necesariamente articuladas entre sí.

\section{Conflictos en la Divulgación y Comunicación de la Ciencia}

Algunos de estos conflictos vinculados a la divulgación de la ciencia tienen que ver con que muchos opinan que la divulgación, puede subestimar a la ciencia en cuanto a que el lenguaje especializado de la última, no es asunto para profanos; a su vez los divulgadores aducen, que es inútil usar sus palabras ininteligibles, aunque éstas tengan significados precisos. Por otro lado, están quienes, subestiman a la divulgación de la ciencia dado que, en el esfuerzo por traducir los hallazgos, descubrimientos científicos y hacerlos accesibles a amplias mayorías, los desdibuja y malinterpreta.

Lo lingüístico aporta que cuanto menos preciso es el discurso, más polisémico resulta, entonces, el receptor del mismo podrá atribuirle distintos significados. Esto podría contribuir a perder la calidad de la comunicación y de la transmisión conceptual que ésta procura. La Posmodernidad mues- 
tra, que no existe la homogeneidad de las audiencias en ningún caso, aunque sean seleccionadas por tal o cual situación (personas que acuden a un museo, grupos de determinado nivel académico, como en este caso). BORDIEU (1985) cita a Compte, quien escribió acerca de la metáfora del tesoro, referido a un "tesoro depositado por la práctica de la palabra en los sujetos que pertenecen a la misma comunidad". CHOMSKY (1965) se refirió a la teoría lingüística, expresando que "se ocupa fundamentalmente de un locutor-auditor ideal, inserto en una comunidad lingüística completamente homogénea, que conoce su lengua perfectamente y al abrigo de los efectos gramaticalmente no pertinentes como limitaciones de la memoria, distracciones, deslizamientos de atención o errores de resultado en la aplicación de su conocimiento de la lengua..." lo que en realidad introduce la noción saussuriana de "la lengua como unidad política", aunque guarda silencio sobre la cuestión de las condiciones económicas y sociales de la adquisición de la competencia (definida por él mismo como conocimiento de la gramática) legítima y de la constitución del mercado donde se establece e impone esta definición de lo legítimo e ilegítimo. Es HABERMAS el que devela que la fuerza de las palabras está vinculada a los grados de represión y al grado de desarrollo de las fuerzas productivas.

La práctica no crítica de la comunicación de la ciencia, puede partir de supuestos de homogeneidad y legitimidad de la "comunidad lingüística" a la que se dirige, que son producto de la dominación política sostenida, respaldada y reproducida por las instituciones con capacidad de imponer su reconocimiento universal a la lengua dominante, constituyendo y reforzando las condiciones que establecen relaciones de dominación lingüística. Por tanto, corre el riesgo de atender al uso o no uso de las palabras por las palabras mismas, desconociendo las "relaciones de fuerza" (illocutionary force) que se verifican en forma transfigurada, y no por las condiciones institucionales en cuanto a su utilización.

Desde un análisis sociológico, e histórico existen un conjunto de presupuestos. BORDIEU, (2000) en una entrevista planteó que "las estructuras mentales son estructuras sociales interiorizadas, hay muchas probabilidades de introducir en la oposición entre lo escrito y lo oral, una oposición completamente clásica entre lo distinguido y lo vulgar, lo culto y lo popular de tal manera que lo oral tiene muchas posibilidades de ser investido de todo un aura populista.". Es más, existiría una cierta noción implícita de que la enseñanza oral está jerarquizada en áreas como política y derecho, mien- 
tras que estaría desjerarquizada en áreas como las de la ciencia y la técnica. Bordieu plantea en la misma entrevista "dar armas más que dar lecciones" y reflexiona acerca de lo que

Parece ser una de las condiciones prácticas de toda relación de comunicación verdadera, que quien tiene la palabra, quien tiene el monopolio de hecho de la palabra, imponga por completo el arbitrario de su interrogación, el arbitrario de sus intereses. La conciencia de lo arbitrario de la imposición de la palabra se impone cada vez más hoy día, tanto a quien tiene el monopolio del discurso como a quienes lo sufren. ¿Por qué en determinadas circunstancias históricas, en determinadas situaciones sociales, resentimos con angustia y malestar este abuso de autoridad que siempre implica tomar la palabra en situación de autoridad o, si se prefiere, en situación autorizada, constituyendo la situación pedagógica el modelo de esta situación? (BORDIEU, 2000, p.1)

La contrapartida para el receptor es la difusa promesa de que el producto obtenido a través de la recepción del discurso, le reportará beneficios y ventajas y su no aceptabilidad, en contraste, sanciones y devaluación en el mercado comunicacional, donde se juega el valor de quien habla, en directa relación a la competencia lingüística de la que dispone.

En forma abreviada Bordieu, expresa su pensamiento cuando dice "de forma rápida y abstracta, la comunicación en situación de autoridad pedagógica supone emisores legítimos, receptores legítimos, una situación legítima, un lenguaje legítimo." Y agrega: “En una situación de crisis, este sistema de créditos se desploma..."

Los comunicadores científicos estamos construyendo un "pasillo" para la comunicación de la ciencia que puede ser tanto más estrecho o amplio, en la medida que tomemos conciencia de nuestra situación desafiante. Posicionados desde una postura que contemple la inclusión, la aceptabilidad de mensajes en una ida y vuelta entre personas, se posibilitará la transformación de situaciones de dominación en situaciones de liberación. Es posible ganar entonces un lugar efectivo en la comunicación de la ciencia, al traer algunos saberes y ponerlos a la par de otros, de modo que los participantes evalúen como valioso lo que creemos que merece ser integrado al conocimiento general humano.

Es por todo ello, que en la concepción del trabajo como divulgadoras de la ciencia en general y como comunicadoras en esta videoconferencia en particular, apelamos a la emocionalidad, a lograr la empatía con quienes participan en 
nuestros eventos para luego introducirlos en los contenidos científicos.

\section{En busca de una estructura...}

La prealimentación es la "búsqueda inicial que hacemos entre los destinatarios de nuestros medios de comunicación para que nuestros mensajes los representen y reflejen" (KAPLÚN1998:78-79). "Más que preocuparse por recoger una hipotética "comunicación de retorno" en la que se sitúa la reacción o respuesta del oyente o lector con posterioridad a la recepción del mensaje, la comunicación educativa debiera procurar sobre todo poner al destinatario al inicio del proceso, originando los mensajes, inspirándolos. “.”KAPLÚN (1992:98).

Nos preguntamos y repreguntamos acerca de quienes nos verían y escucharían, paso inicial e ineludible para el que desea una comunicación genuina pensada desde la alteridad. Serían visitantes del Museo Universum (prestigioso museo mejicano), que podrían ser ocasionales o el tipo de "público cautivo" de alguna institución escolar dependiente de la UNAM, de la que forma parte.

Nosotras... personas de otras edades, de otro país, con otras culturas debíamos hallar los puentes o nexos con ellos. Bastó indagar acerca del conocimiento que podrían tener sobre nosotros, habitantes del Uruguay, si conocían nuestra música y costumbres para evidenciar esta diversidad. Pensamos mucho en cómo organizar una comunicación de alrededor de una hora de duración, que no decayera en interés y que lograra atraerlos, a la vez que informar, jugar, interactuar, entretener, convirtiendo la actividad en una experiencia de acercamiento humano. Fue así que seleccionamos contenidos que implicaran momentos en el desarrollo del evento, que alternaran distintas posibilidades de mediación. Se buscó acortar distancias con los estudiantes mejicanos, al compartir con ellos los testimonios escritos de Charles Darwin, cuando tenía 23 años, acerca de los hechos sociales y los hombres y mujeres de la época (opiniones que hoy podrían ser expresadas en su contexto por cualquier joven en alguna esquina latinoamericana). Les contamos cómo era Darwin como estudiante y los conflictos con su padre por no tener la vocación de médico o predicador. También, su pasión exploradora, y sus virtudes de joven inquieto, estudioso de los asuntos de su interés y lector entusiasta. Se mostró a México y América del Sur, como vecinos geográficos no muy lejanos, antes de la aparición del Océano Atlántico, en el período Jurásico Tardío. Se realizaron menciones a lo largo de la 
exposición, a lugares y escenarios de la ciudad de México, debido a que una de nosotras vivió allí un tiempo. Mencionamos, que uno de los artistas cuya música fue escuchada en uno de los videos exhibidos, Don Alfredo Zitarroza, fue aclamado en sus presentaciones a lo largo de su exilio en México.

Las impresiones que Darwin volcó acerca de nuestro territorio y su gente, quedaron en el cuaderno Banda Oriental y en varios capítulos de "El Viaje del Beagle". Sus opiniones y reflexiones están plenas de juicios de valor, y no exentas de crítica, ironía y sentido del humor. Refieren a los comportamientos humanos y los hechos políticos acaecidos en nuestros territorios, constituyendo un verdadero retrato social de época. Como tal fueron comunicados y valorados. Muestran al joven Darwin con principios de gran valía ética. Las observaciones geológicas zoológicas y botánicas vertidas en estos registros mostraron tener importancia fundacional en la construcción de la Teoría de la Evolución. Significativos fueron para este proceso, su observación y estudio de las calandrias y sus hallazgos de restos fósiles de la megafauna. Se dedicó un espacio destacado a presentar reconstrucciones de sus esqueletos y representaciones de estos grandes animales encontrados en nuestro territorio, procurando provocar sorpresa y causar un efecto de contraste por sus dimensiones a escala.

Los tres videos exhibidos buscaron mostrar algo similar a lo que él vio, y acercan algunos de los lugares explorados por Darwin. Uno de ellos, sobre nuestra costa oceánica, se acompañó de la descripción que Darwin hizo de los sonidos emitidos por los lobos de mar, a los que comparó con ganado cuando los oyó llegando a esas costas del actual Uruguay. Los otros dos, elaborados para la ocasión, refieren a tierra firme, donde estudió la geología del lugar y desenterró fósiles. Los audiovisuales incluyeron: el primero música de fusión de tango-jazz y rock a cargo de Bajofondo, reciente ganador de los Premios Emmy y el segundo, música tradicional (milonga) con letra y música de Alfredo Zitarroza. Se hizo mención de los artistas, como otra forma de presentar a nuestro país.

En el transcurso de la actividad, y con la finalidad de cambiar el ritmo de la misma, se habilitó un espacio para el juego y la participación, a través de la propuesta de dos desafíos que movilizaran la observación y la inferencia. Se usó "frío- frío", "tibio- tibio" y "caliente- caliente" (en caso de alejarse o acercarse a la respuesta correcta). Exhibimos piezas fósiles de megafauna, cuya colecta fue realizada por nosotras mismas en el territorio uruguayo (hueso de toxodonte y placas de gliptodonte), como las que podría haber 
hallado el mismo Darwin en su momento, y les pedimos que buscándolas en una imagen procedieran a su posible ubicación en el animal. Los aciertos y errores tuvieron una distribución muy democrática entre los participantes provocando festejos y vivenciando el hecho que todos tenemos parte del conocimiento y estamos habilitados para resolver planteos nuevos.

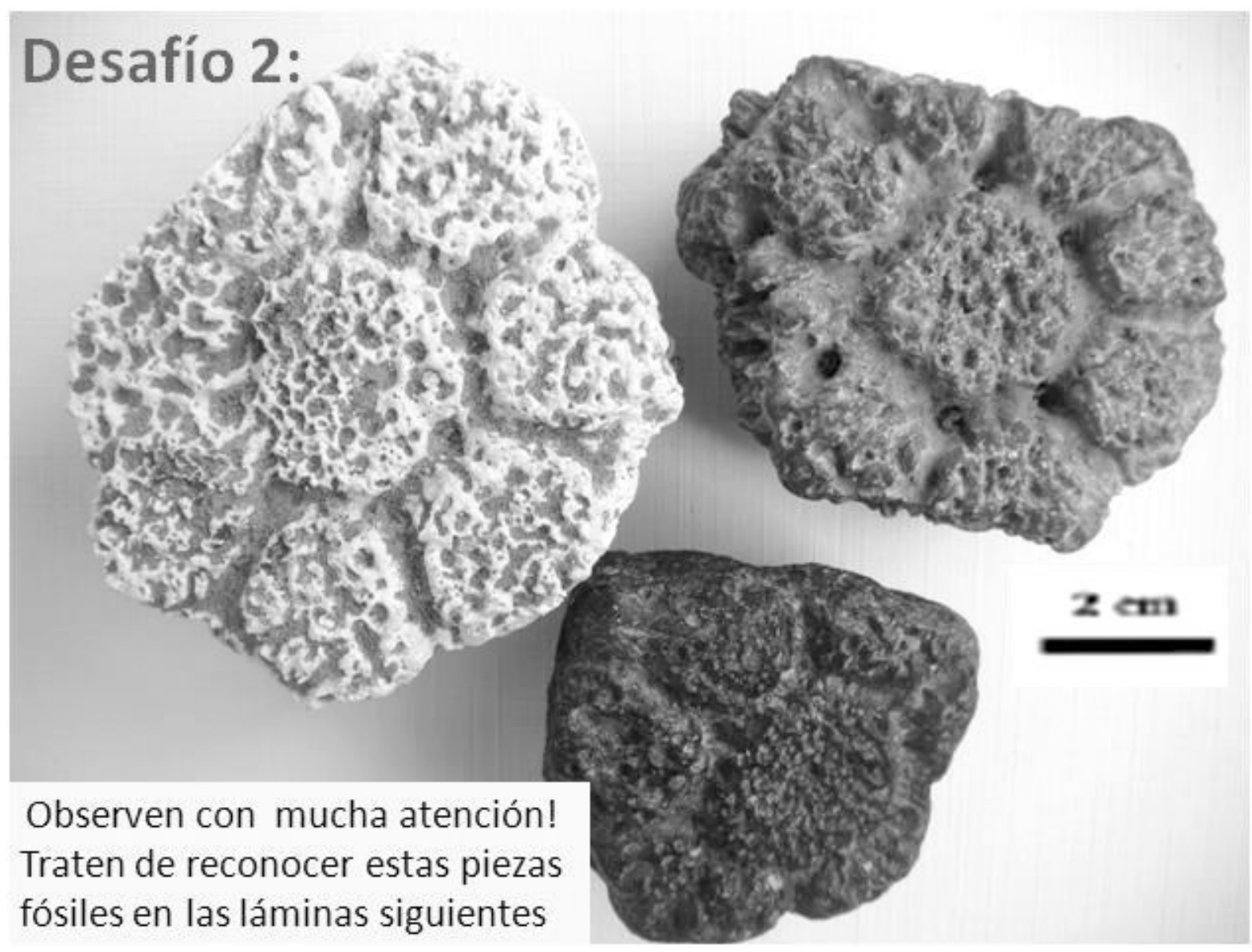

Deliberada y concientemente procuramos hacer una contribución a la educación, a la que consideramos inseparable de la divulgación científica. En particular, al destinar la última parte de la videoconferencia, al capítulo "Darwin hoy", se mostró un hallazgo hecho en el Uruguay, que tuvo repercusión mundial. Nos parece interesante compartirlo con los lectores de esta revista, ya que se trata de la más antigua dinosaurio hembra que aparece con un huevo embrionado en su interior. Este ejemplar es del mismo género que otro, aparecido en la Formación Aratí, comprendida dentro del Geoparque Paleorrota, en el área geográfica de la Universidad Federal de Santa María. El mesosauro encontrado en la Formación Mangrullo, en el Departamento de Cerro Largo, en Uruguay, es pariente próximo del Mesosaurus brasiliensis de la Formación Aratí. Este último a su vez es similar al encontrado en el sur de 
África, en la Formación Whitehill, de la Cuenca de Karoo, territorio geológicamente correlacionado (equivalente) a la formación Aratí y a la Formación Mangrullo. Este descubrimiento había convertido a la Formación Aratí y a la cuenca del Paraná, en mundialmente famosos, a los que ahora se agrega la Formación Mangrullo, por constituirse en una de las evidencias más fuertes de la deriva continental y de la existencia de un territorio común de dispersión de estas especies estrechamente emparentadas, antes de que los actuales continentes americano y africano se separaran. Representa una contribución más, a la confirmación de la Teoría de la Evolución, al mantener y respaldar la vigencia de la misma, un siglo y medio después de su enunciación.

La Dra. Graciela Piñeiro paleontóloga uruguaya a cargo de las investigaciones, comentó el hallazgo: "Es la hembra de reptil preñada más antigua que se conoce. Los embriones de Uruguay están dentro de lo que parecen ser huevos, totalmente arrollados, envueltos por una membrana, e incluso uno tiene un 'diente de huevo' para romper la cáscara”. Sería la transición entre anfibio y reptil. Esto permite entender la transformación de un huevo no amniota en uno amniota, de lo que no había noticias. “... podemos decir ahora, que los amniotas, (los reptiles más primitivos), podrían haber puesto huevos cuyos embriones estaban en un estado muy avanzado del desarrollo y que el huevo eclosionaba en horas. La otra opción es que podrían haber sido vivíparos." El registro del inicio de animales nacidos vivos retrocedió 60 millones de años, según el (journal) Historical Biology, 2012. 


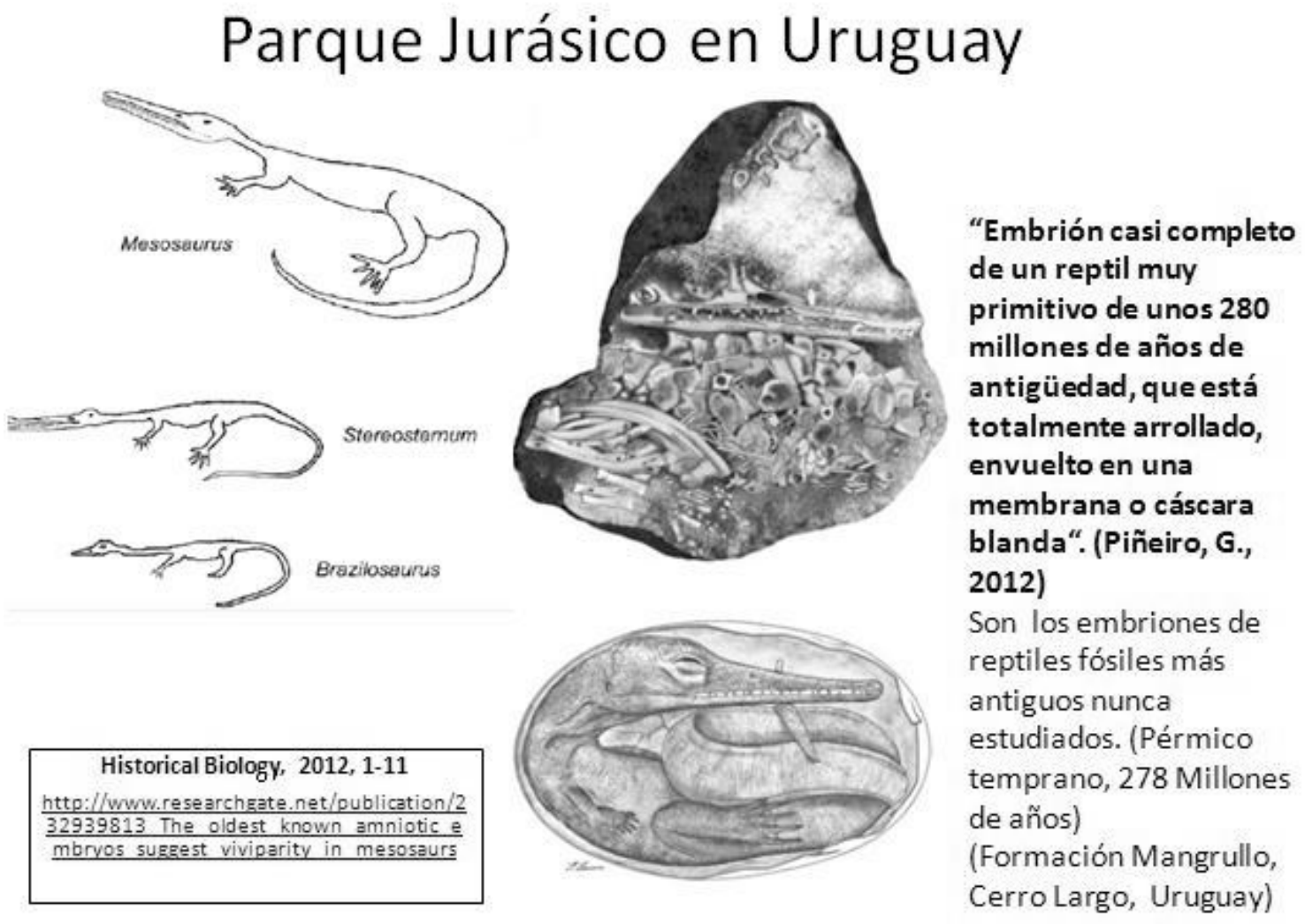

\section{Acerca de la enseñanza de la Teoría de la Evolución}

WAGENSBER (2000) dice que las exposiciones se pueden basar en emociones y no sólo en conocimientos previos. La enseñanza sobre la vida puede ser algo muy atractivo. En particular si es una narración que se aborda desde los testimonios de un explorador muy joven que emprendió un viaje alrededor del mundo a partir del cual produjo una monumental teoría sobre el origen y la evolución de las especies que cambió para siempre la organización de la ciencia y la filosofía. Exponer y explicar las ideas que sustentan esta Teoría puede ser difícil si la gente conoce poco sobre ella.

Una forma de ingresar al campo de dicha Teoría puede ser la presentación de su autor como persona. Humanizar la información, ofrecerla de una manera lo más llana y precisa posible y mostrar la evidencia que sustentó y sustenta la investigación sobre la misma. Estar dispuesto a los cambios, a practicar la duda razonable y a mejorar la comprensión de la realidad, hace al desarrollo de las mentalidades científicas y a la posibilidad de transformación intelectual de nuestras sociedades. La selección de los contenidos verbales, escritos o imágenes tiene que tener potencia para la construcción culturalcientífica. "La Biología puede ser entendida como un bien cultural si se la ve como la ciencia depositaria de las explicaciones acerca de la vida en la Tier- 
ra con las connotaciones que en el campo antropológico, social y filosófico, ésta tiene." (ROJAS, L., 2009) Por todo ello, la ciencia es considerada como un contexto para la educación para la ciudadanía. Se sabe que las cuestiones relacionadas con la ciencia influyen de manera poderosa en la vida contemporánea JARMAN, Mc CLUNE, (2010) acuerdan con JENKINS(2004), en que "se afirma que cierto conocimiento de la ciencia es una condición sine qua non de la ciudadanía en el mundo moderno" JENKINS(2004:165). Por ello la divulgación científica se vuelve una potente herramienta para la educación personal, social, para la salud y para la educación para el desarrollo sostenible.

En concordancia con lo expresado la mediación pedagógica se potencia cuando se da oportunidad al participante de poder establecer relaciones con la realidad y la cotidianeidad y se le permite la posibilidad de ir más allá de lo estrictamente expuesto, llevándolo a una reflexión sobre los otros y sobre sí mismo. Desde un punto de vista epistémico, la "ciencia posnormal" (FUNTOWICZ Y RAVETZ, 1993) tiene en la confrontación de argumentos y en la democratización de las participaciones, algunos de sus pilares fundamentales. La enseñanza y el aprendizaje de las ciencias ha de incluir aquello que permita la comprensión y evaluación de los contextos en los cuales el conocimiento se ha dado, así como también las consecuencias que tendrán las posturas del ciudadano del mañana; habilitar el ensayo de las formas de promover la negociación y el consenso en sus futuras decisiones. Los ejercicios de una práctica de ciencia posnormal pueden convertirse en potentes simuladores de la realidad social que refuercen el sistema de cosas imperante o que promuevan su transformación. La ciencia normal, (KHUN, 1962) estaría representada por el aprendizaje de los paradigmas científicos con mayor o menor sensibilidad a lo contextual social.

En esta oportunidad, la videoconferencia procuró incluir mucho de lo informal ya que se dirigió a jerarquizar al mismo nivel tanto al proceso como al logro. Sin descuidar características de una muestra como contenidos y presentación, se enfatizó la comunicación atendiendo a los participantes, proponiéndoles dialogar, haciéndoles preguntas personales e informales, con actitud de escucha, a sus expresiones demostrativas de sus estados de ánimo y a la disposición a interesarse por lo allí mostrado. Se trata de montar un escenario para que se logre una "comunidad de intercambio", con sus componentes informales y formales, de naturaleza social y colaborativa, donde la comprensión se construye en el diálogo con otros. Por ello valoramos la interactividad en más de un aspecto; no sólo porque la muestra 
cumpliera con algo de "hands on", sino porque permite también, la comunicación propia de los medios masivos, con la de tipo interpersonal.

Según los aportes de la neurobiología, las personas alcanzan un aprendizaje cognitivo relativo al qué, al cómo y al por qué. Un aprendizaje psicomotor, relacionado con la manipulación, la coordinación, un aprendizaje afectivo, asociado a las actitudes, intereses y motivaciones.

Es posible con este enfoque, comenzar a desdibujar la contradicción entre educación formal tradicional y comunicación, transitando desde la primera, en general, una propuesta enfocada cognitivamente, descontextualizada, pasiva, con un fin en sí misma, casi siempre individualista, a un enfoque de comunicación holístico (cognitivo, afectivo, psicomotor), contextualizado, basado en la práctica, interdependiente de otras actividades, colectivo y colaborativo.

Para ello, se apeló a habilidades variadas que ofrecieran espacio para distintos estilos de aprendizaje. Fueron concebidas para que en su mayoría, estimularan la curiosidad, la atención, observación, el razonamiento y la inferencia y que no fuera muy difícil su respuesta, con algún grado de dificultad mayor, en particular en cómo es construida verbalmente la respuesta. Consistieron en:

* Encuentre a qué lugar corresponde (ubicar un hueso de Toxodon en una foto de su esqueleto)

* Identifique qué parte del cuerpo es y a qué animal pertenece (Se muestran placas de Gliptodonte y varios animales y se pide que identifiquen dónde y en cuál animal se encontrarían)

\section{Transversalidades:}

La interdisciplina debiera ser uno de los puntos básicos de la comunicación científica.

En ese espíritu, se cuidó la presentación en sus aspectos: histórico-sociales, geológicos, geográficos, identitarios, taxonómicos y evolutivos de las especies así como en los éticos. Evaluamos que la concepción de ciencia que se desprende de nuestra propuesta es la vigente: "La ciencia es una actividad condicionada social e históricamente, a través de la cual se construye un conocimiento temporal y relativo que cambia y se desarrolla permanentemente." HODSON (1994:299-313) 


\section{Evaluación:}

Existen posturas que consideran al aprendizaje como un diálogo entre el individuo y su ambiente cultural y social; se trata de un esfuerzo contextual para lograr significados, que le permitan sobrevivir y relacionarse críticamente con su entorno de modo de guardar un equilibrio entre adaptación y transformación, de acuerdo a sus necesidades individuales y colectivas. La pregunta alrededor del aprendizaje ya no es qué aprende un individuo como resultado de una experiencia educativa, sino cómo contribuyó esa experiencia educativa a mejorar la comprensión. Por tanto, no centramos la evaluación en el modelo de déficit sino que intentamos determinar su impacto. Se tomaron dos decisiones: solicitar una evaluación externa de un colega (en lo contextual y en aspectos puntuales), y otra, proveniente de quienes nos habían invitado (las autoridades de Universum). Se sumaron, la de otros colegas asistentes, más la nuestra personal. Nos interesó recoger opiniones e impresiones sobre la actividad, y sobre el acto en sí mismo del acercamiento a la enseñanza de la Teoría de la Evolución. Se tomaron en cuenta:

* Contextualización temporal: presente-pasado. Pasado-presente.

* La presentación como herramienta visual del diálogo en base a imágenes.

* Uso del tiempo. Previsión ante emergentes no deseados, como demoras en las conexiones con los videos, o por distorsiones de imagen o sonido entre otras. Dichas contingencias fueron sorteadas con éxito, al establecer diálogos, leer fragmentos escritos por Darwin, o hacer preguntas a la audiencia.

* Aportes e información acerca de los videos, su confección, su música. Las historias y los contextos de los lugares filmados. Incorporación de composiciones y músicos nacionales relevantes.

* Anticipación. Explicaciones previas que anuncian lo que se verá en los videos, y contribuyeron a su comprensión.

* Interactividad con el auditorio que estimuló la sorpresa, el interés y la reflexión.

* Selección de textos de Darwin y de su tataranieto, así como de científicos uruguayos que actualmente hacen hallazgos que respaldan la Teoría evolutiva.

* Citas de científicos de la talla de Ernst Mayr que conecta una especie de pájaros presentes en Uruguay con potentes postulados de Darwin: el de ancestro común y extinción

* Notoria intención de establecer nexos, acortar distancias y evaluar en el espacio de preguntas. 
Todas las evaluaciones recibidas por este equipo mostraron valoración muy satisfactoria de la actividad.

\section{ALGUNAS REFLEXIONES DEL EQUIPO DIVULGADOR...}

¿Cómo hacer aparecer la tarea y la realización de una producción a lo largo de su proceso de construcción que, sin desestimar cuestiones teóricas, ponga especial énfasis en las maneras prácticas de comunicarlo? Esta pregunta matrizó nuestro trabajo, y posibles respuestas están dadas en este artículo. No es más que lo llevado adelante, entre otras pensadas. Quizá la contribución mayor a nivel personal, haya sido el hecho de reconocernos como productores de conocimiento a partir de la reflexión sobre la integración y proposición de la gran cantidad de información y saberes necesarios que profundizamos para elaborar este evento de comunicación de la ciencia.

\section{AGRADECIMIENTOS:}

Al equipo de Universum que nos invitó y posibilitó esta experiencia. A los compañeros del IFD de Florida. A CinEduca e Informática, a E. Saraibe, E. Sordini y J. Castro docentes administrativos por su habitual disposición y a la Directora de la Institución Mtra. Isabella Urdampilleta por su permanente apoyo a nuestras actividades y por su lectura atenta y opinión autorizada en la revisión de este trabajo.

\section{BIBLIOGRAFÍA}

BORDIEU, P., Cuestiones de Sociología. Madrid, Istmo, 2000. pp. 95-111, Disponible en: http://www.slideshare.net/marcelak/lo-que-significa-hablar-pierre-bourdieu Consultado 4/4/2014

BORDIEU, P., ¿Qué significa hablar? Ed. Akal 1985, p. 17-18

CABERO, J., La videoconferencia como instrumento educativo. En: Cabero, J. Nuevas tecnologías aplicadas a la educación, Madrid, Síntesis (2000) p. 97-110.

CHOMSKY, N., En: BORDIEU, P., Op. cit. P. 17-18

JARMAN, R., MCCLUNE. B., El desarrollo del alfabetismo científico, Ediciones Morata, 2010, p. 2, Disponible en: http://books.google.com.uy/books?id=_SQbAgAAQBAJ\&p$\mathrm{g}=\mathrm{PA} 35 \& \mathrm{lpg}=\mathrm{PA} 35 \& \mathrm{dq}=$ Rensberger+\%281997\%29\&source=bl\&ots=Jbf-LMgOFK\&sig=D 7vUHj8TCWnC3k5PsbQ_tL3kUU\&hl=es\&sa=X\&ei=09Q1U_L6Es3isATdsIDwCw\&ved=oCEQQ6AEwAw\#v=onepage\&q=Rensberger\%20\%281997\%29\&f=false Consultado 4/4/2014 KAPLÚN, M., Comunicación entre grupos. El método del cassette-foro. Buenos Aires:Hu- 
manitas. (1990)

KAPLÚN, M., A la educación por la comunicación. La práctica de la comunicación educativa. Santiago de Chile: UNESCO/OREALC, (1992)

KAPLÚN, M., Una pedagogía de la comunicación. Madrid: Ediciones de la Torre. (1998).

MAYR, E., What evolution is, Basic Books, 2001

PIÑEIRO, G., et al., The oldest known amniotic embryos suggest viviparity in mesosaurs, Historical Biology, iFirst article, 2012, 1-11, Disponible en: http://www.researchgate. net/publication/232939813_The_oldest_known_amniotic_embryos_suggest_viviparity_in_mesosaurs Consultado 4/4/2014

POLINO, C., Medir la percepción pública de la ciencia en los países iberoamericanos. Aproximación a problemas conceptuales, Revista Iberoamericana de Ciencia, Tecnología, Sociedad e Innovación Número 5 / Enero-Abril 2003, Disponible en: http://www.oei. es/revistactsi/numero5/articulo1.htm Consultado 4/4/2014

Documento Proyecto Iberoamericano de Indicadores de Percepción Pública, Cultura Científica y Participación Ciudadana, (OEI- RICYT) del Programa CYTED, Revista Iberoamericana de Ciencia, Tecnología, Sociedad e Innovación, Disponible en: http://www. oei.es/revistactsi/numero5/documentos1.htm Consultado 4/4/2014

RENSBERGER, B., Covering science for newsapwpers, En: JARMAN, R., MCCLUNE. B., 2010, Op. cit. p. 35

ROJAS, L., Muestra interactiva de Arqueología y Paleontología del Uruguay, Congreso REDPOP 2009, Montevideo. Uruguay, Disponible en: http://latu21.latu.org.uy/espacio_ ciencia/es/images/RedPop/Museologia/Mo8.pdf Consultado 4/4/2014

WAGENSBERG, J., Principios fundamentales de la Museología científica moderna, 2000, Disponible en: http://www.ben.es/publicacions/bmm/55/cs_qc05.htm. Consultado $4 / 4 / 2014$ 


\section{Mariela Fontaiña Gaminara}

Maestranda en Didáctica de Ed. Media -Biología. ANEP-Universidad de la República Oriental del Uruguay (UdelaR) Dr. en Medicina y Tecnología Veterinaria, UdelaR, 1985 Profesora Tecnológica, Instituto Normal de Enseñanza Técnica INET, Montevideo, Uruguay Docente Formador de Maestros y Profesores, (CFE-ANEP) Uruguay

Divulgadora, ponente, organizadora y diseñadora de muestras museísticas, cafés científicos y campamentos científicos.

\section{Lucía Ruth Rojas Méndez}

Maestranda de la Universidad Nacional del Comahue, Provincia de Neuquén, Rep. Argentina

Lic. en Ciencias Biológicas, Universidad de la República Oriental del Uruguay, 1989

Profesora de Ed. Media-Biología, Instituto de Profesores Artigas, Montevideo, Uruguay

Docente Formador de Maestros y Profesores, (CFE-ANEP) Uruguay

Divulgadora, ponente. Organizadora y diseñadora de publicaciones científicas, muestras museísticas, cafés científicos y campamentos científicos. 